\title{
Sources and Possible Causes of Errors and Misconceptions in Operations of Integers
}

\author{
Madihah Khalid ${ }^{{ }^{*}}$, Zulmaryan Embong ${ }^{1}$ \\ ${ }^{1}$ Department of Curriculum and Instruction, Kuliyyah of Education International Islamic University Malaysia, MALAYSIA \\ *CORRESPONDENCE: $\triangle$ madihahkhalid@iium.edu.my
}

\begin{abstract}
This research investigated students' sources and causes of errors and misconception in solving routine problems involving addition, subtraction, multiplication, and division of integers. This qualitative study involved observation of eight Year 7 classes and interviews with the respective classroom teachers. Sixteen Year 7 students who exhibit errors when solving the problems given in the Error Identification Integer Test (EIIT) were also interviewed to probe their thinking. The different types of errors were categorized according to how they were construed. The sources of errors were found to stem from carelessness, poor basic knowledge such as the inability to multiply and divide even the whole numbers, inability to assimilate concepts of integers since they are used to the schema of whole numbers, and rule mix-up which is also the result of surface understanding. Teachers were questioned about common errors and possible reasons for these errors made by their students. The main cause of errors and misconceptions is superficial understanding, which was most probably due to teachers rushing to complete the extensive syllabus, and consequently, students resorted to memorizing rules because of surface understanding. Teaching episodes were found to lack multiple-representation, creativity, as well as cooperative learning and active learning.
\end{abstract}

Keywords: Malaysian 13 year-olds, causes of errors, sources of errors, concepts of integers, Integer misconception

\section{INTRODUCTION}

Difficulties in solving basic operations involving directed numbers or integers has been widely documented throughout the world especially in those involving addition and subtraction (Badarudin \& Khalid, 2009; 2008; Goh, Tengah, Shahrill, Tan, \& Leong, 2017; Hayes \& Stacey, 1998; Khalid et al., 2018; Makonye \& Fakude, 2016; Sadler, 2012; Schindler \& Hubman, 2013; Steiner, 2009; Widjaya, Stacey, \& Steinle, 2011). This is a cause for concern because the topic on integers forms a fundamental background needed for success in algebra and higher-level mathematics. In Malaysia, the topic of integers is first taught when the students are in Year 7 (about twelve to thirteen years old). Students who completed secondary school should ideally possess a thorough knowledge and understanding of the complete real number system which includes negative numbers. However, some students fail to achieve this as they accept some procedures such as the rule of signs without understanding the proper justification for it. The finding by Kloosterman (2012) shows that a quarter of 13year-old students were not able to add positive and negative numbers correctly while half of them were unable to divide integers correctly.

Basic operations of integers seem simple, yet, according to Alsina and Nelson (2006), the students tend to get confused and they struggle when asked to solve simple mathematical problems. It is difficult for the

Article History: Received 2 September $2019 \bullet$ Revised 23 October $2019 \bullet$ Accepted 23 October 2019

(C) 2020 by the authors; licensee Modestum Ltd., UK. Open Access terms of the Creative Commons Attribution 4.0 International License (http://creativecommons.org/licenses/by/4.0/) apply. The license permits unrestricted use, distribution, and reproduction in any medium, on the condition that users give exact credit to the original author(s) and the source, provide a link to the Creative Commons license, and indicate if they made any changes. 
students because they have been taught to follow rules and procedures in a very abstract manner without going through the models for better conceptual understanding. It is desirable that students should grasp the fundamentals of mathematics so that they can learn the advanced mathematical topics with ease. Besides, having good mathematical skills will ultimately save the students' time in the examination and reduce the need for tutoring or remediation. Moreover, since each process builds upon prior knowledge and successful application of these skills, it is extremely important that the fundamentals must be solid for every school student.

\section{PROBLEM STATEMENT}

Malaysian students' performance in the "Trends in Mathematics and Science Study" (TIMSS) and "Program in International Student Assessment" (PISA) has resulted in a great worry that it would undermine the nation's aspiration in realizing the STEM initiatives of 60:40 ratio of students taking science to arts at upper secondary and university levels (Bernama, 2014). Much has been talked and reported about the Malaysian students' achievements in these two international tests and the major concern is pertaining to the teaching and learning of mathematics in the school system. Many Malaysian students seem to depend on rote memorization in learning mathematics and the teachers seem to teach the students using rules and procedures in order to get the correct answers, hence, neglect their conceptual understanding (Lim, 2011). She expressed that many teachers teach the students for the sake of passing the examinations instead of emphasizing on the understanding of concepts. Undoubtedly, she recommended that this situation occurred due to the challenging nature of teaching for conceptual understanding which requires extensive preparations and good content knowledge from the teachers. Lim also viewed that Mathematics teaching in many schools in Malaysia can still be characterized as teacher-centered.

On the other hand, the Ministry of Education recommended the focus of five elements in teaching and learning of mathematics which include problem-solving, communication, reasoning, mathematical connections and application of technology (MOE, 2003). However, in the case of operations of integers, teachers prefer to provide students with rules to be memorized, and then drill them with enough practice to make them stick to the rules. This practice might lead to poor understanding and misapplication of the rules since the students will get confused with so many rules that they have to remember. For example, those who answer $6+(-2)=-$ 8 argue that 2 added to 6 is 8 , yet there is a minus sign which makes the answer to be negative. The fact that the rules are only applied to the multiplication of a positive and a negative integer and not for the addition of integers is lost without proper understanding.

However, it is important to explore the possible reasons of why students answer the question in such a way and it is more interesting if the errors form a certain pattern that can explain the students' thinking or their conceptual understanding. In many situations, the students tend to use their previous knowledge and strategies that they used to apply for whole numbers, when dealing with addition and subtraction of integers. This makes the teachers' approaches in teaching integers as an important investigation in understanding how teachers think when they teach this subject and what their level of knowledge in this topic is. By conducting such an investigation, a proper solution could be identified to overcome more problems with regards to students' misconceptions of integers. An earlier paper of this research has reported students' performance from a related diagnostic test, where it was found that students performed worst in the subtraction of integers and best in the multiplication of integers (Khalid et al., 2018).

This study is a part of the diagnostic exercise to identify gaps in teachers' instructional practices and students' conceptual understanding and skills as promoted in the Malaysian Education Blueprint (2012). Teachers are expected to understand their students' thinking processes and should be able to correct them at the earlier stage so that the problems shall not persist as they grow up into adults. It is evidenced by Sadler (2012) who found a significant proportion (38\%) of adult students between 18 to 25 years of age, still gave wrong answers to routine problems on operations of integer due to many different reasons which could be resolved if certain measures were taken to improve the situation.

In addition, teachers lack in terms of instruments which can be used to diagnose the types of errors that students perform in solving problems involving operations of integers. Some studies related to this topic (such as Egadowatte, 2011; Rubin, Marcelino, Mortel, \& Lapinid, 2014; Sadler, 2012; Schindler \& Hubmann, 2013) seem to rely on self-constructed instruments that have not yet been verified or validated. Therefore, this research produces a validated diagnostic instrument that can be used to identify students' errors and misconceptions in solving problems involving addition, subtraction, multiplication, and division of integers, 
together with a full guideline or manual of how to use the instrument. The instrument was developed based on some existing researches and also this specific research. Teachers may use the instrument and the suggestions of how to teach and counter students' misconception by emphasizing on their conceptual understanding.

Briefly, this paper aims to present the sources and causes of errors in the operations of integers, as mentioned above. In achieving this aim, the types of errors that the students performed and already identified were confirmed via interview, and the causes of errors examined. By the end of the paper and a teaching framework is proposed. The instrument was also validated to ensure that it is legitimate for students' use and for teachers to be able to distinguish the misconceptions in solving the integer problems. In particular, the research question for this particular paper is

What are the sources and possible causes of error in solving routine problems in the operations of integers?

\section{METHOD}

\section{Research Design}

To explore the sources of errors and misconception that students commit when solving basic problems on operations of integers, a qualitative approach was employed in order to get rich data. A variety of data sources from interviews (with teachers and students), observation, field notes and document analysis (such as the syllabus, teachers' lesson plan, and students' work) were examined to determine the sources of errors. This was done after examining students' mistakes from a diagnostic test called error identification integer test (EIIT).

\section{Participants}

This research involved Year 7 (Form 1) students in public Malaysian schools. To answer the research question, eight classes were observed, and teachers from each of the classes were consequently interviewed. The eight classes were chosen based on the geographical location to get an overall picture of how the topic of integers is taught around the country. Two classes (representing the urban and rural schools) were selected to represent each state of peninsular Malaysia, namely Terengganu (Eastern part), Johor (South part), Selangor (Middle part) and Kedah (Northern part). The schools were selected using cluster sampling. Sixteen students were interviewed and the participants for the interviews were sampled purposively, according to the interesting and curious mistakes that they have made.

\section{Instruments}

Two interview protocols (one for teachers and one for students) were prepared with semi-structured questions in order to guide the researchers in the research. Also, the observation checklist was utilized to ease the researchers to collect the observation data for the eight classrooms. All instruments were pilot tested to ensure suitability and validity.

\section{Research Procedure and Ethics}

For this research study, permission was requested in a hierarchical manner. Initially, the researchers seek permission to conduct research from the Research Department of the Malaysian Ministry of Education. Then the researchers brought the letter to each state Department of Education involved in the research. The researchers were directed to the district Department of Education of the selected schools to again seek permission to meet the principals and the teachers who are involved in the study. Finally, permission was also requested from the parents of the sixteen students who were interviewed.

\section{RESULT}

\section{Student Interview}

Table 1 shows a summary of findings when all sixteen student participants were interviewed and probed on the mistakes that they made. The mistakes were categorized accordingly into four categories, namely because of 1) carelessness 2) poor basic knowledge such the ability to multiply and divide even the whole numbers 3 ) inability to assimilate concepts of integers since they are used to the schema of whole numbers, 
and 4) rule mix-up - rote learning such as memorizing rules that led to rule mix-up (Khalid et al., 2018). Another category has been added, which is surface understanding.

Table 1. Test Items and Students' Justification for Answer Given

\begin{tabular}{|c|c|c|c|}
\hline Student & Errors & Student's Reasons & Types of Errors \\
\hline 1 & $\begin{array}{l}\bullet \text { Q8: }-2-6=8 \\
\bullet \text { Q16: }-6-(-2)=4 \\
\bullet \text { Q32: }-8 /-4=-2\end{array}$ & $\begin{array}{l}\text { - The answer cannot be negative } \\
\text { - Ignore the sign and subtract the nos. } \\
\text { - Factor out }-1\end{array}$ & $\begin{array}{l}\text { - Surface understanding } \\
\text { - Inability to assimilate } \\
\text { - Poor knowledge } \\
\end{array}$ \\
\hline 2 & -Q8: $-2-6=8$ & - Negative minus negative become positive & - Rule mix-up \\
\hline$\overline{3}$ & $\begin{array}{l}-\mathrm{Q} 8:-2-6=8 \\
\bullet \mathrm{Q} 16:-6-(-2)=4\end{array}$ & $\begin{array}{l}\text { - Negative and negative gives positive } \\
\text { - }-6-(-2)=4 \text { is negative minus negative becomes positive. } \\
\text { Ignoring the signs }\end{array}$ & $\begin{array}{l}\text { - Rule mix-up } \\
\text { - Poor knowledge and } \\
\text { rule mix-up }\end{array}$ \\
\hline$\overline{4}$ & $\begin{array}{l}-\mathrm{Q} 8:-2-6=8 \\
\cdot \mathrm{Q} 16:-6-(-2)=4\end{array}$ & $\begin{array}{l}\text { - Negative meets with negative become positive } \\
\text { - } 2 \text {-ves becomes +ve (pointing to the signs of the } \\
\text { numbers) then } 6 \text { - } 2\end{array}$ & $\begin{array}{l}\text { - Rule mix-up } \\
\text { - Poor knowledge and } \\
\text { rule mix-up }\end{array}$ \\
\hline 5 & $\begin{array}{l}-\mathrm{Q} 8:-2-6=8 \\
\text {-Q16: }-6-(-2)=-8\end{array}$ & tive + negative $=$ positive & $\begin{array}{l}\text { - Rule mix-up } \\
\text { - Poor knowledge }\end{array}$ \\
\hline$\overline{6}$ & $\begin{array}{l}-\mathrm{Q} 8:-2-6=8 \\
\text {-Q16: }-6-(-2)=4 \\
\text {-Q19: }-2 \mathrm{x} 6=-12 \\
\text {-Q32: }-8 /-4=-2\end{array}$ & $\begin{array}{l}\text { - Negative meets with negative become positive } \\
\text { - } 6-2=4 \text {, ignoring the signs } \\
\text { - Although correct, the student didn't know how to get } \\
\text { it } \\
\text { - Because there is negative, so the result must be } \\
\text { negative }\end{array}$ & $\begin{array}{l}\text { - Rule mix-up } \\
\text { - Inability to assimilate } \\
\text { - Surface understanding } \\
\text { - Rule mix-up }\end{array}$ \\
\hline 7 & $\begin{array}{l}-\mathrm{Q} 16:-6-(-2)=8 \\
-\mathrm{Q} 19:-2 \mathrm{x} 6=12 \\
-\mathrm{Q} 32:-8 /-4=-2\end{array}$ & $\begin{array}{l}\text { - Negative meets with negative becomes positive. } \\
\text { There is a formula for addition \& subtraction } \\
\text { - Ignored the sign } \\
\text { - } 8 / 4=2 \text {, so it changes to }-2 \text { because there is negative }\end{array}$ & $\begin{array}{l}\text { - Rule mix-up } \\
\text { - Inability to assimilate } \\
\text { - Poor knowledge }\end{array}$ \\
\hline 8 & $\begin{array}{l}-\mathrm{Q} 8:-2-6=8 \\
- \text { Q19: }-2 \mathrm{x} 6=-12 \\
-\mathrm{Q} 32:-8 /-4=2\end{array}$ & $\begin{array}{l}\text { e meets with negative becomes positive } \\
\text { h correct, student didn't know how to get it }\end{array}$ & understanding \\
\hline$\overline{9}$ & $\begin{array}{l}-\mathrm{Q} 8:-2-6=8 \\
-\mathrm{Q} 16:-6-(-2)=-4 \\
\text {-Q19: }-2 \times 6=8 \\
\text {-Q33: }-6 /-2=-3\end{array}$ & $\begin{array}{l}\text { - Negative minus negative equals positive } \\
\text { - Although correct, student could not explain it } \\
\text { - Wrong operation (addition) } \\
\text { - Factor out }-1\end{array}$ & $\begin{array}{l}\text { - Rule mix-up } \\
\text { - Surface understanding } \\
\text { - Carelessness } \\
\text { - Poor knowledge } \\
\end{array}$ \\
\hline$\overline{10}$ & $\begin{array}{l}-\mathrm{Q} 8:-2-6=8 \\
-\mathrm{Q} 16:-6-(-2)=-\varepsilon\end{array}$ & $\begin{array}{l}\text { - Negative minus negative equals positive } \\
\text { - } 6 \text { minus }-2 \text { become }-8 \text {, since the answer carries the } \\
\text { sign of the bigger number }\end{array}$ & understanding \\
\hline$\overline{11}$ & $\begin{array}{l}\bullet Q 8:-2-6=8 \\
\bullet Q 16:-6-(-2)=4 \\
\end{array}$ & $\begin{array}{l}\text { - Negative minus negative equals positive } \\
\text { - Negative }- \text { negative = positive }\end{array}$ & $\begin{array}{l}\text { ix-up } \\
\text { e understanding }\end{array}$ \\
\hline 12 & $\begin{array}{l}-\mathrm{Q} 8:-2-6=-8 \\
-\mathrm{Q} 16:-6-(-2)=-4\end{array}$ & $\begin{array}{l}\text { - Although correct, student can't explain how -ve } \\
\text { happen correctly. Just put - ve because there is -ve } \\
\text { - Although correct, student explained }(6-2=4) \text {. Then put } \\
\text {-ve because there is a negative sign }\end{array}$ & - $\mathrm{Sr}$ \\
\hline 13 & -Q8: $-2-6=8$ & - Negative + negative $=$ positive & - Rule mix-up \\
\hline 14 & -Q16: $-6-(-2)=8$ & - Negative - negative $=$ positive & ix-up \\
\hline$\overline{15}$ & $\begin{array}{l}-\mathrm{Q} 8:-2-6=-4 \\
-\mathrm{Q} 16:-6-(-2)=-8\end{array}$ & $\begin{array}{l}\text { - Negative }+ \text { negative }=\text { positive } \\
\text { Negative - negative }=\text { negative, because there are } \\
\text { three negatives, then the answer is negative }\end{array}$ & $\begin{array}{l}\text { - Rule mix-up } \\
\text { - Rule mix-up }\end{array}$ \\
\hline 16 & $\begin{array}{l}-Q 8:-2-6=-4 \\
-Q 16:-6-(-2)=\end{array}$ & $\begin{array}{l}\text { - Negative + negative = negative } \\
\text { - Confused over the rules of parenthesis and ignored } \\
\text { one of the negatives }\end{array}$ & $\begin{array}{l}\text { - Rule mix-up } \\
\text { - Poor knowledge }\end{array}$ \\
\hline
\end{tabular}

\section{Carelessness}

The simplest mistake made by some of the students were carelessness. Student 9 saw the multiplication sign as addition and made mistakes in calculating the answer. One or two students even assume that the division sign " $\div$ ” is “+” because they look quite similar. However not many students do this (note: in the original diagnostic test, “”” was written as “־”, 
Table 2. Observation Themes and Sub-themes

\begin{tabular}{|c|c|}
\hline Main Themes & Sub Themes \\
\hline Lacks multiple representations & $\begin{array}{l}\text { - No concrete representation } \\
\text { - } 2-3 \text { representation }\end{array}$ \\
\hline Lacks cooperative learning & $\begin{array}{l}\text { - Pair } \\
\text { - The whole class }\end{array}$ \\
\hline Lacks active learning & $\begin{array}{l}\text { - Discussion with whole students } \\
\text { - Monitoring } \\
\text { - Teacher as a discussion leader }\end{array}$ \\
\hline $\begin{array}{l}\text { Lacks incident of creative and critical } \\
\text { thinking }\end{array}$ & $\begin{array}{l}\text { - Teacher-centred } \\
\text { - Reinforce rules and procedures } \\
\text { - Using whiteboard only } \\
\text { - Not giving time to think of other methods }\end{array}$ \\
\hline
\end{tabular}

\section{Poor knowledge}

Poor knowledge here means errors made by students because of poor basic knowledge such as confusion with parenthesis where students do not know how to remove the parenthesis (student 16), wrongly applying the factorization such as $-6-(-2)=-(6+2)=-8$ by student 5 , or $-6 /-2=-1(6 / 2)=-3$ by student 9 . Here, we can see that students are weak in basic knowledge of parenthesis and also factorization, and hence perform an error. Some other students (not the ones interviewed) are even weak in multiplication and division.

\section{Can't assimilate concept}

Here students were still treating of integers as whole numbers. Hence, they will ignore any negative signs and operations, and perform the calculation for whole numbers. Some will completely ignore the negative signs of the numbers while some will add the negative sign to whatever answer they manage to produce. This was done by students 1, 6 and 7, where he ignored the signs and just subtract (or multiply) the two numbers.

\section{Rule mix-up}

This error was performed by many students, in fact, the majority of the students that were interviewed. This is a specific case of surface understanding where students just remember rules such as negative and negative becomes positive and apply it indiscriminately. Some apply this rule when adding or subtracting integers although this rule is used when multiplying or dividing numbers. Fourteen out of the sixteen students interviewed committed this error as they did not understand how and where to apply the rules. This is the consequence of teaching rules before students are given the chance to understand the concept.

\section{Surface understanding}

The authors added this category because some students just could not explain how and why they solve certain problems on integers, such as student 1 . Some gave correct answers, but when asked to explain how they did it, they could not. Students 6, 8, 9 and 12 could not explain why they gave certain answers. For student 12 , when solving -6-(-2), he initially ignores the signs of the numbers, perform the operation and added a negative to the answer because the numbers carry negative signs.

In general, it can be seen that many students commit a mixture of errors. Many errors are due to rule mixup and some are due to surface understanding.

\section{Observation Data}

The researchers went to schools to observe the teaching and learning of integers. The observation was needed in order to understand the classroom setting, teachers' methodologies in teaching, students' engagement towards integers, and students' behaviour during the lessons. Table 2 illustrates the themes from the observation checklist that was used throughout the classroom observations in terms of what is expected from the classroom teaching.

From the observation checklist and field notes, it was noted that in general, teachers devote two weeks (5 hours) to complete the topic of integers. Within five hours of teaching ( 2 weeks), most teachers prefer to use only the number line approach as a teaching strategy. All of them used direct instruction and classroom lecture style in explaining the concept of integers. The main themes are explained as follows: 
Table 3. Demographic Details of Interviewed Teachers

\begin{tabular}{ccccc}
\hline Teacher & Age & Experience & Highest Qualification & Gender \\
\hline 1 & 35 & 11 & First Degree & Female \\
\hline 2 & 43 & 18 & First Degree & Female \\
\hline 3 & 40 & 15 & First Degree & Female \\
\hline 4 & 31 & 3 & First Degree & Female \\
\hline 5 & 38 & 13 & First Degree & Female \\
\hline 6 & 48 & 23 & First Degree & Male \\
\hline 7 & 33 & 8 & First Degree & Female \\
\hline 8 & 27 & 4 & First Degree & Female \\
\hline
\end{tabular}

\section{Lacks multiple representations}

From the observation, it was found that teachers used between two to three representations such as verbal and visual or verbal, and visual and real-life representations. The real-life representation is in the form of analogy and this method was used by only four teachers. Examples of their analogies include the concepts of ships in the sea, a lift with the underground basement, the theory of debt, and the idea of a thermometer. All of these concepts were explained using the whiteboard. Apparently, the teachers did not transform an abstract idea to the concrete. As a consequence, some students were unable to grasp the concepts of integers as they have difficulties to understand them.

\section{Lacks cooperative learning}

Cooperative learning is one of the elements that the researchers were emphasizing in this study. However, from the observation, no evidence of any cooperative learning was found. With only a total of five hours to complete the topic on integers, teachers are not expected to perform elaborate activities. Therefore, to make it easy and convenient for both teachers and students, the former prefers to have simple activities such as solving problems in pairs or the whole class. For them, this can save more time compared to the use of hands-on activities or group discussion. Also, with the huge number of students in a class, it is difficult for teachers to handle their students.

From the observation, it can be seen that all teachers monitored their students' understanding by praising their students' works or achievements in solving questions on integers. In addition, students worked according to teachers' guidance and teachers acted as discussion leaders. This was to ensure that the classroom was not interrupted and was well-organized. Meanwhile, besides the lack of activities, teachers do not give students enough time to work on their own to solve the problems. Teachers rush to finish the important basic skills in mathematics since they think that the students will know them once the topic is completed. Students only follow what the teachers do without asking any question.

\section{Lacks incident of creative and critical thinking}

From the observation, all teachers were found to use the number line approach in teaching the operations of integers. They would typically ask students to memorize the rules and procedures. There is no room for creative and critical thinking to take place in the teaching and learning process. For teachers, the students must remember how the number line works. The students must know which direction they should move, either to the left side or to the right side. The teachers expect the students to understand the concept of a number line with a lot of practice. Rules were thrown out and expected to be remembered. For them, when students focus on specific rules or procedures, they will gradually become more comfortable with the rules, and finally would be able to solve similar problems. However, students simply tend to follow the rules and procedures without understanding most of the concepts of integers.

\section{Teachers' Interview}

Table 3 shows the demographic information of the eight teachers interviewed.

The questions posed to the teachers are mainly to determine whether teachers are aware that some students are having problems in understanding integers, and the possible causes on why this topic is a gave the students these problems. Table 4 shows the themes and sub-themes from the teachers' interview. 
Table 4. Themes and Subthemes of the Teacher-Interview

\begin{tabular}{ll}
\hline Main Themes & Sub Themes \\
\hline Parenthesis & - Think that parenthesis is not important \\
Misapprehension & - Ignore parenthesis \\
& - Did not know the function of the parenthesis \\
& - Did not consider the role of parenthesis \\
& - Confusion between symbol and value when there is a parenthesis \\
\hline Poor knowledge of the & - Unable to differentiate between the subtraction symbol and the negative sign. \\
basic concept & - Think that they are the same \\
& - Tnable to understand the concept of negative values \\
\hline Calculator Hooking & - Teachers teach students how to use the calculator, since calculator use is allowed \\
& - Students do not want to memorize the multiplication table \\
\hline Superficial & - Obty understand when in the classroom \\
Understanding & - Do not get sufficient exercise \\
& - Time constraint \\
& - Too much syllabus to complete \\
External Limitation & - Lifferent students' abilities \\
& - School activities, holidays, natural disasters
\end{tabular}

\section{Parenthesis misapprehension}

Teacher 2, Teacher 3, Teacher 4, Teacher 5 and Teacher 6 said that their students always commit mistakes when they solve questions with parenthesis. For example, Teacher 2 and Teacher 6 stated that their students always forget the function of the parenthesis when solving a question. They tend to just solve the question directly without considering the value with or without parenthesis. As a result, they end up making a big mistake when answering the question.

"Hmm, it is like that. Students got confused. They did not open (deal with) the parenthesis first" $(2: 78)$

"Like today, when it involves operations, the students appear confused with the function of parenthesis, so I need to teach them again" (6:20)

Teacher 3 also added,

"The students do not understand how parenthesis works, when to use it and the right way to use it. When I am explaining, they get confused whenever there is a parenthesis" $(3: 24)$

Meanwhile, Teacher 4 always reminds her students to remember the rules. She also tells her students that parenthesis means multiplication. However, her students will still make mistakes. This is because they just ignored the function of parenthesis that might influence the final answer. However, when it comes to using the calculator, the students can answer the question correctly because they just have to follow and punch in the exact signs and symbols of the questions.

"One more problem, when there are parentheses, for example (-2)+(-3), they can get the answer correctly by using the calculator. Although I would remind them that the parenthesis means multiplication, they only remember it at that time. But in the exam, hmm." (4:68)

Teacher 5 also has difficulties in explaining to her students the concept of parenthesis. The students are always confused with the symbol and operation when there is a parenthesis. For them, parenthesis does not give any value to the question. Therefore, the mistake keeps recurring. Hence the teacher needs to explain that parenthesis is used when subtraction or addition meets a negative number but not a positive number 
"The questions with parenthesis; when subtraction or addition meets a negative, we need the parenthesis but not if a subtraction or addition meets a positive number. But when subtraction or addition meets with a negative value, the symbols need to change too" $(5: 30)$

Therefore, based on the teachers' interviews, it shows that most of the students are struggling with parenthesis. Some of them were confused with the concept and the function of parenthesis. Others were unable to relate it with multiplication. This shows a specific problem of poor basic knowledge. Poor knowledge is further explained below.

\section{Poor knowledge of basic concepts}

From the interviews, five out of eight teachers agreed that students always commit errors when they are solving addition and subtraction questions. One of the reasons for the errors is due to a confusion in the symbol and value. Many students are confused with the subtraction symbols and negative values. Teacher 3 and Teacher 6 mentioned,

"Okay, when they do not understand the concept, for example, if they need to change the symbol for addition of negative 6 , when they do not understand the concept, the result is wrong. They are supposed to subtract but they add instead. When they are supposed to add, they subtract. Those are the problems in integers. When the students learn algebra, they will get more confused because they do not understand integers" (3:32)

Teacher 3 believes that the most difficult task in teaching integers is to make the students understand the concept of operational symbols and negative sign. The students always make mistakes because they think the subtraction symbol and the negative sign are the same. Meanwhile, Teacher 6 has difficulties in making the students understand how to handle the situation of negative signs and subtraction symbols when both are in the same problem. The students tend to make an error when both the sign and symbol are combined.

"Meanwhile, for the operation like addition and subtraction, they have a problem when they come across those two symbols" (6:28)

Teacher 8 also faced the same problem. Her students get confused with the symbol and operation itself.

"Usually, they are confused with the symbols and operation itself" (8:32)

The same teacher continues to state that the students are unable to differentiate between them and believe that the subtraction symbol and negative values are the same.

“They are unable to differentiate between operation and sign" (8:56)

"They think that subtraction and negative are the same" (8:58)

The concept of subtraction alone confuses many students. Teacher 7 stated that the students are not able to understand the concept of negative values, in which how can a smaller number be subtracted with a bigger number and becomes a negative number.

"When I asked them to solve the question, they do not understand and wrongly swap the addition and subtraction operation. Like in class $1 \mathrm{D}$, when we ask what is 3 minus 8 ? They say, "cannot solve teacher!" In their mindset, small numbers cannot be subtracted with a big number" (7:26)

Students are used to dealing with whole numbers and were told during their primary school years that it is not possible to take away a bigger number from a smaller number. Hence this is set in their mind in that the concept of a negative number does not exist. Therefore, they are unable to solve integers-related problems involving negative numbers.

\section{Calculator hooking}

Another cause of errors in this research relates to students' dependency on the calculator. According to Teacher 5 and Teacher 6, they prefer to make their students understand the concepts. However, since the schools allow the use of calculators, they will teach them to use the calculator after teaching the concept. 
"We are allowed to use calculators, so we just use it. But basically, I will ask them to memorize the multiplication table. For a weak class, I will ask them to check the answer using the multiplication table. They will solve it although it will take some time. In addition, I will ask them to write the multiplication table first and then find the solution. But since we can use the calculator, so, we just let them use it" (5:126)

"Yes, they need to understand it first. For example, when I ask the students ' 4 divided by 2 ,' they will use the calculator to find the answer. This is because, nowadays, in their mind, all calculations can be done with the use of a calculator" (6:52)

However, since the use of calculators is allowed in secondary schools, some of the teachers consider this as an opportunity to let their students use the calculator instead of making them understand the concept. It also makes teaching and learning smoother. According to Teacher 2, her students are allowed to use the calculator as long as they know about integers.

"Because nowadays students use a calculator. So, we cannot see the effect (number line method), as long as they know integers" (2:138)

Teacher 3 also agrees with Teacher 2 , and said that nowadays students can use calculators. Hence, the students just need to key in the numbers and get the result.

“That's it. Nowadays, we can use a calculator. All those minus 6” (3:26)

Teacher 8 mentioned that his/her students do not want to memorize the multiplication table since they can use calculators.

"Yes, they can use it (calculator) nowadays. That is why they do not want to memorize the multiplication table" (8:52)

From the interview, calculators may be a reason why students commit errors when solving operations of integers. Sadly, although they are allowed to use the calculator, their answers may not be correct all the time.

\section{Superficial understanding}

This is another cause of error identified in the interview with teachers. Five of the teachers believe that the students are unable to answer the questions because of their surface understanding of integers. Teacher 1 stated that his/her students can only solve questions that have been addressed in the classroom. However, when they are asked to answer other types of question, they are unable to do so.

"Yes, they can understand the questions we did in front of the class. But when we give exercises, they will ask, "what should we do teacher?" "how do add and subtract work?" Some of them do not even care anymore" (1:109)

Teacher 3 also faced the same problem. The students are not able to understand the concept of symbol and negative value.

"Ha, they did not understand the concept. Supposedly the symbol will remain, so it becomes negative 8 . The students are confused" (3:22)

The same teacher furthers stated that the students do not have any problem with multiplication because they just need to memorize two rules. Besides, students can use the calculator. However, without a calculator, they are unable to answer a question. However, there are those who provide wrong answers even though they use the calculator. This is a recurring problem among students.

"Students do not have problems with multiplications because they just need to remember two rules. If the number has a different sign, thus it is negative. If the number has the same sign, the answer is positive. In addition, they can use the calculator to solve problems in multiplications. But some of them even give the wrong answer even with the use of a calculator" (3:32)

However, Teacher 6 believes that students are unable to understand the new concept because they do not have enough exercise. This is one of the reasons why they cannot perform when the question is different. 
"Probably the students do not have enough exercise. They can answer the question in class, but will get confused to solve it elsewhere" (6:24)

The same teacher continued to say that the students are not familiar with the concept of the number line method. They are unsure of which way should they move, either the right side or the left.

"For subtraction operations, when the value is positive, they do not know on which side they should move" (6:36)

Therefore, a superficial understanding of the concept of integers leads to misconceptions among students. The students are not able to see the whole picture in the operations of integers.

\section{External limitations}

Other causes of errors in the operation of integers can be termed as external limitation such as time constraint. From the interviews, all teachers use the number line method as their teaching preference for the addition and subtraction of integers. Meanwhile, for multiplication and division, they would ask students to memorize the multiplication table and the rules of multiplication and division. Some teachers stated that they have limited time to focus only on integers in their teaching. According to Teacher 1, she would just provide her students with the rules and procedures to solve the integer problems. This is because they need to finish all the 13 topics in the textbook within a certain time frame. Thus, it is impossible to merely focus on one topic and neglect the other topics.

"I asked them to memorize something, and they would just memorize that thing. We cannot be stuck at only one subtopic. We have 13 topics, so we need to rush. So, I would just ask them to memorize and give lots of exercises. That's it" (1:83)

Teacher 8 also agreed with Teacher 1. Since all the teachers need to follow the lesson plans set by the Ministry of Education, with 13 topics altogether, therefore, teachers feel rushed and they need to finish the syllabus within the given timeframe.

"We need to be faster because we have lesson plans to follow. So, it is a bit rushed but we must finish it" (8:78)

For teachers, this is the reason to explain their inability to focus more on only one topic and to not finish the other topics. Therefore, they prefer to use any method of teaching that can reduce the time.

Another limitation is the mixing of students' abilities in one class. According to Teacher 1, the current ministry favour to place students of differing levels of ability in one class. Hence, a classroom may have students with strong cognitive abilities and students with weak cognitive abilities. Therefore, teachers have to spend more time to cater to the differing abilities of the students.

"But nowadays the classes are the same. There is no academically-excellent and weaker classes. Each class is comprised of students with different levels of abilities (1:58)

However, for public schools, sometimes the teachers will have a large number of students. Teacher 1 has at least 40 students in a single class. This makes it difficult for Teacher 1 to focus on only one topic.

"And then, in one class, we not only have twenty students, but you can also see many
students in one class. When we are involved with many students, we cannot focus on only
one person and even after class or during the class activities. We can just spend five
minutes with each. All our time used for teaching" (1:87)

In addition, school activities serve as a distraction that teachers have to deal with, apart from school holidays and sometimes natural disasters such as flooding. According to Teacher 2,

"We want the students to understand but we need to finish all the topics. They (the ministry) already organized the schedule and topics with a good flow. They just did not consider other school activities. There are a lot of school activities. Then, there are natural disasters like flood, and school public holidays, and sometimes unexpected holidays" $(2: 134)$ 
Teacher 5 agrees with the statement of Teacher 2 and said that school activities slowed the teaching and learning process. With half an hour class, it is difficult for the teachers to finish all the topics in the given time.

"Hmm. With half an hour of lesson, school events and holidays..." (5:160)

Teacher 2 further said that the 13 topics prepared by the Ministry of Education are only relevant if there is nothing disturbing the teaching and learning time.

"The 13 topics are enough for one year of school. But only if there are no other programmes. However, we are involved with many programmes, natural disasters, and other problems that may hinder our aim to finish the syllabus" (2:134)

Furthermore, school activities could lead to students' absenteeism. Thus, the affected teachers need to repeat the missed lessons so that the students will not be left out. Catering to the needs of weaker students also disrupts the lesson's progress.

“Then we need to follow students' abilities. Not every student can understand something within three hours. Weak students need more time to understand and at the same time we cannot wait for them (due to the syllabus)" (2:134)

From the interviews conducted, the teachers agreed that parenthesis misapprehension, poor mathematical language, calculator hooking, superficial understanding and external limitations are the causes of students' errors and misconceptions in the operations of integers. These causes are difficult to alleviate because teachers think that they are natural occurrences that are out of their control.

\section{DISCUSSION}

From the researchers' perspective, the main cause of errors and misconception in solving routine problems involving operations in integers are related to the external limitations. The teachers' complaint about time constraint is quite valid since they have to cover thirteen large topics of the Year 7 syllabus. Coupled with school activities, public holidays and holidays due to natural disasters in some areas of the country, they have limited time to make sure that students understand the topic. Some classes has a larger number of students of different abilities which requires a lot of time to focus on individual students. Hence teaching is done more in a lecture style, with limited activities.

Data from observation shows that important elements of mathematics teaching such as multiple representations, cooperative learning, active learning and creative teaching for critical thinking occurring at a minimal level in the observed classrooms. Hence it is not surprising that some students were seen to have superficial or surface understanding. Unfamiliarity with integers causes students to be unable to assimilate the concept of integers into their schema of whole numbers and this is made worse when the teaching is rushed. That is the reason why many teachers resorted to giving students rules, hoping that the students will be able to understand later as they solve more problems. But this does not happen as students misapply the rules that they cannot understand. They get mixed-up and apply the multiplication and division rules to addition and subtraction. The errors are worse for students who have poor basic knowledge such as knowledge of using parenthesis, factorization, and even basic multiplication and division.

Some teachers and students think that since calculator usage is allowed in Malaysian schools starting from Year 7, it is not important to understand the concept of basic operations in integers. For them what is more important is the students manage to get the correct answer. This was revealed from the teachers' interview where they prefer the use of calculators among students instead of providing the right concept of integers, since they have 13 topics in the syllabus to cover. The dependency on calculators is made worse in some cases when students do not use their thinking or do any mental calculations. The calculator prevents students from discovering and understanding underlying mathematical concepts and instead encourages them to randomly try different operations without understanding what they are doing. This problem exacerbates when students start to learn algebra. Good knowledge of operations in integers is important for manipulation of numbers and letters in algebra.

Student participation is a worry for the teachers. In a mixed-ability class, teachers will find that the stronger students generally participate more than the less advanced students. This may be due to the shy 
nature of the less advanced students or because they are very aware that they are not the top students in the class and are scared of giving the incorrect answer. Lack of participation can also cause the less advanced students to perform even less (or worse) in class. Hence we need to emphasize cooperative learning, with worthwhile activities that apply all five representations mentioned by Lesh (1979), especially the concrete representation for students to understand more. With concrete representation, students will be more active and will be able to use their mathematical thinking which is needed.

School students in Malaysia were taught rules which they memorize but some students misapply the rules since they do not understand them. The favourite rule is the rule for multiplication of integers that they memorize by heart "negative and negative give positive", "negative and positive or positive and negative gives negative" which is often misapplied as can be seen in Table 1. Another misapplication is when the teacher said that the answer should carry the sign of the bigger number which is only correct for certain cases. An example to illustrate this would be $-6+2=-4$. But when the problem is $2-(-6)$, the answer is 8 and it will not carry the negative sign of 6 . This can be a reminder to teachers, that is not to generalize.

While this shortcut is probably introduced by teachers with good intentions, it does not provide the student with the conceptual knowledge to understand why subtracting a negative number results in a positive value. This supports Alsina and Nelsen's (2006) claim that students tend to get confused and struggle when they are asked to solve simple and routine mathematical problems.

\section{CONCLUSION}

In summary, from the data collected from classroom observation, teachers' interviews and students' interviews, there are several sources of errors and the root causes that lead to the misconceptions and errors while dealing with operations of integers that we can learn from. The findings from this study emphasize the importance of teaching for understanding. The researchers would like to suggest that teachers adhere to the recommendations that can be derived from the implication of the observation data. Try to incorporate the following elements in coming up with meaningful activities in their mathematics lessons:

1) Active learning

2) Cooperative learning

3) Multiple representations

4) Creative lessons that will make students think critically

There are no short cuts in teaching for understanding. Hence we proposed a teaching framework that includes the four elements above in the teaching of integers.

\section{ACKNOWLEDGEMENT}

This research was supported by [FRGS/1/2016/SSI09/UIAM/02/10]. We would like to thank the Ministry of Education for providing us with the grant and make this research possible.

\section{Disclosure statement}

No potential conflict of interest was reported by the authors.

\section{Notes on contributors}

Madihah Khalid - Department of Curriculum and Instruction, Kuliyyah of Education International Islamic University Malaysia, Malaysia.

Zulmaryan Embong - Department of Curriculum and Instruction, Kuliyyah of Education International Islamic University Malaysia, Malaysia. 


\section{REFERENCES}

Alsina, C., \& Nelsen, R. B. (2006). Math Made Visual: Creating Images for Understanding Mathematics. United States of America: The Mathematical Association of America. https://doi.org/10.5948/UP09781614441007

Badarudin, B. R. H., \& Khalid, M. (2008). Using the Jar Model to Improve Students' Understanding of Operations on Integers. Proceedings of icme-11-topic study group 10 research and development in the teaching and learning of number systems and arithmetic, 85.

Bernama, N. (2014). Malaysia aims for 60 percent of children to take up STEM education. Retrieved on 30 January 2019 from http://english.astroawani.com/malaysia-news/malaysia-aims-60-percent-childrentake-stem-education-najib-44509

Egodawatte, G (2011). Secondary School Students' Misconception in Algebra (Unpublished PhD thesis). University of Toronto, Canada.

Goh, L. S., Tengah, K. A., Shahrill, M., Tan, A., \& Leong, E. (2017). Teaching and learning of integers using hands-on versus virtual manipulatives. Paper presented at the $3^{\text {rd }}$ International Conference on Education 2017 (ICEDU 2017), Kuala Lumpur, Malaysia, 20-22 April 2017.

Hayes, B., \& Stacey, K. (1998). Teaching negative numbers using integers tiles. Melbourne, Australia: Heinemann.

Khalid, M., Ibrahim, M. B., Saad, S., Othman, J., Mohd Yussuf, Y., Embong, Z., (2018). A Preliminary Study on Form 1 Students? Errors and Misconception in Operations of Integers. Proceedings of National Education Deans' Council Seminar [Medc 2018], Unisza, 7-8 November, 2019.

Kloosterman, P. (2012). Mathematics Performance of 13-Year Olds in the United States: 1978 to 2004. Paper presented at the Research Presession of the Annual Meeting of the National Council of Teachers of Mathematics April 24, 2012, Philadelphia

Lesh, R. (1979). Mathematical learning disabilities: considerations for identification, diagnosis and remediaton. In R. Lesh, D. Mierkiewicz, \& M. G. Kantowski (Eds.), Applied Mathematical Problem Solving. Ohio: ERIC/SMEAC

Lim, C. S. (2011). Assessment in Malaysian School Mathematics: Issues and Concerns. Paper presented at the meeting of The APEC-Tsukuba International Conference, Japan.

Makonye, J. P., \& Fakude, F. (2016). A Study of Errors and Misconceptions in the Learning of Addition and Subtraction of Directed Numbers in Grade 8. SAGE Open. SAGE Open (October-December, 2016), 110. https://doi.org/10.1177/2158244016671375

Malaysian Education Blueprint. (2012). Malaysian Education Blueprint 2013-2025. Preschool to PostSecondary Education. Putrajaya: Ministry of Education

Ministry of Education Malaysia [MOE]. (2003). Mathematics Syllabus for Integrated Curriculum for Primary School. Curriculum Development Centre.

Rubin, R. J., Marcelino, J. M., Mortel, R., \& Lapinid, M. R. (2014). Activity-Based Teaching of Integer Concepts and Its Operations. Paper presented at DLSU Research Congress 2014 De La Salle University, Manila, Philippines.

Sadler, J. T. (2012). The Positives about Negatives: A Study of Errors and Misconceptions with Integer Operations in Adult Education (Unpublished master's thesis). State University of New York.

Schindler, M., \& Hubmann, S. (2013). About Students' Individual Concepts of Negative Integer - In Terms of the Order Relation. Proceedings of Congress of European Research in Mathematics Education, 6-10 February, Turkey.

Steiner, C. J. (2009). A study of pre-service elementary teachers' conceptual understanding of integers (Unpublished doctoral dissertation). Kent State University College and Graduate School of Education, US.

Widjaja, W., Stacey, K., \& Steinle, V. (2011). Locating negative decimals on the number line: insights into the thinking of pre-service primary teachers. Journal of mathematical behavior, 30(1), 80-91. https://doi.org/10.1016/j.mathb.2010.11.004

http://www.iejme.com 